from lung adenocarcinoma treated with bevacizumab and chemotherapy. Case Rep Ophthalmol Med 2015; 2015: 142408.

4 George B, Wirostko WJ, Connor TB, Choong NW.

Complete and durable response of choroid metastasis from non-small cell lung cancer with systemic bevacizumab andchemotherapy. I Thorac Oncol 2009; 4(5): 661-662.

HR Kourie, J Antoun and J Kattan

Faculty of medicine, Saint Joseph University

Hematology-Oncology, Beirut, Lebanon

E-mail: hampig.kourie@hotmail.com

Eye (2015) 29, 1628-1629; doi:10.1038/eye.2015.174; published online 18 September 2015

\section{Sir, \\ Intravitreal bevacizumab for choroidal metastases: the key to efficacy is simultaneous administration of systemic therapy}

We read the recent case series reported by Maudgil et al ${ }^{1}$ wherein they described their experience with use of intravitreal bevacizumab (IV-Bev) for treatment of choroidal metastases (CM) in five patients and concluded that it is not recommended as the primary treatment for this clinical scenario. We have previously reported encouraging responses with use of IV-Bev in CM from non-squamous non-small-cell lung cancer (NSCLC). ${ }^{2} \mathrm{We}$ had also subsequently carried out a systematic review on use of IV-Bev in CM from lung cancer of whom five had been treated at our centre. ${ }^{3}$ It is important to note that in all of the cases reported/identified by us, IV-Bev was used in combination with some form of systemic therapy. ${ }^{2,3}$ We would like to highlight here that in the series by Maudgil, in three of the four cases in whom progression of ocular lesions was noted while on IV-Bev, no systemic therapy was initiated simultaneously. ${ }^{1}$

Bevacizumab targets angiogenesis, an important pathophysiological basis for tumorigenesis and metastasis, and is approved for systemic use in patients with non-squamous NSCLC but not other histological types of lung cancer. The role of histology in predicting response to IV-Bev for CM from LC is similar to that for use of systemic bevacizumab, and this led us to simultaneously caution against IV-Bev use in CM from small cell lung cancer. ${ }^{3}$ Moreover, in the only patient in our systematic review with non-squamous NSCLC who had progression of CM during treatment with IV-Bev plus first-line chemotherapy, administration of systemic bevacizumab and IV-Bev plus second-line chemotherapy led to regression of $\mathrm{CM}^{2,3}$

We believe that the key to effectiveness of IV-Bev in CM lies in a multidisciplinary approach wherein the treating oncologist initiates the most appropriate form of systemic therapy (chemotherapy or targeted/hormonal therapy) at the same time as the use of IV-Bev by the ophthalmologist. In our opinion, it would be therefore prudent not to hastily conclude about the lack of effectiveness of IV-Bev for CM in general. Despite the relatively small number of patients globally in whom this treatment modality has been used, the biological plausibility for the effectiveness of this drug combined with the encouraging responses so far makes IV-Bev an effective treatment option for local control of CM from non-squamous NSCLC. ${ }^{3}$ We would also tend to believe that $\mathrm{CM}$ from other solid tumors may also have variable degrees of responsiveness to IV-Bev, as has been documented in the literature, including those published in your journal. ${ }^{4-6}$

In conclusion, while we fully agree with that use of IV-Bev for CM should not delay initiation of other treatment modalities, we strongly believe that this implies using the most appropriate form of systemic therapy in combination with IV-Bev rather than not using IV-Bev at all.

\section{Conflict of interest}

The authors declare no conflict of interest.

\section{References}

1 Maudgil A, Sears KS, Rundle PA, Rennie IG, Salvi SM. Failure of intravitreal bevacizumab in the treatment of choroidal metastasis. Eye (Lond) 2015; 29: 707-711.

2 Singh N, Kulkarni P, Aggarwal AN, Rai Mittal B, Gupta N, Behera D et al. Choroidal metastasis as a presenting manifestation of lung cancer: a report of 3 cases and systematic review of the literature. Medicine (Baltimore) 2012; 91: 179-194.

3 Maturu VN, Singh N, Bansal P, Rai Mittal B, Gupta N, Behera $\mathrm{D}$ et al. Combination of intravitreal bevacizumab and systemic therapy for choroidal metastases from lung cancer: report of two cases and a systematic review of literature. Med Oncol 2014; 31: 901.

4 Amselem L, Cervera E, Diaz-Llopis M, Montero J, Garcia-Pous M, Udaondo P et al. Intravitreal bevacizumab (Avastin) for choroidal metastasis secondary to breast carcinoma: short-term follow-up. Eye (Lond) 2007; 21: 566-567.

5 Fenicia V, Abdolrahimzadeh S, Mannino G, Verrilli S, Balestrieri M, Recupero SM. Intravitreal bevacizumab in the successful management of choroidal metastases secondary to lung and breast cancer unresponsive to systemic therapy: a case series. Eye (Lond) 2014; 28: 888-891.

6 Lin CJ, Li KH, Hwang JF, Chen SN. The effect of intravitreal bevacizumab treatment on choroidal metastasis of colon adenocarcinoma-case report. Eye (Lond) 2010; 24: 1102-1103.

N Singh ${ }^{1}$, R Bansal ${ }^{2}$, D Behera ${ }^{1}$ and A Gupta ${ }^{2}$

${ }^{1}$ Department of Pulmonary Medicine, Postgraduate Institute of Medical Education and Research

(PGIMER), Chandigarh, India

${ }^{2}$ Department of Ophthalmology, Postgraduate

Institute of Medical Education and Research

(PGIMER), Chandigarh, India

E-mail: navneetchd@yahoo.com or

singh.navneet@pgimer.edu.in

Eye (2015) 29, 1629; doi:10.1038/eye.2015.176; published online 18 September 2015 